\title{
TECNOLOGIAS DIGITAIS MÓVEIS: UMA TECNOLOGIA POUCO CONHECIDA ENTRE OS PROFESSORES DO ENSINO FUNDAMENTAL E MÉDIO
}

\section{MOBILE DIGITAL TECHNOLOGIES: A LITTLE TECHNOLOGY KNOWN BETWEEN TEACHERS OF FUNDAMENTAL AND AVERAGE EDUCATION}

\author{
Alan Santana Brito \\ Universidade Cruzeiro do Sul / santana.brito@hotmail.com \\ Laura Marisa Carnielo Calejon \\ Universidade Cruzeiro do Sul / lauracalejon@gmail.com \\ Elaine Cristina Ricci \\ Universidade Cruzeiro do Sul / nericcidelima@yahoo.com.br \\ Luciano Soares Gabriel \\ Universidade Cruzeiro do Sul / lussoga@hotmail.com
}

\begin{abstract}
Resumo
O M-learning ou as novas tecnologias de informação e comunicação, mais conhecidas por TICs, estão presentes nos contextos de discussão educacional após 1990. No entanto, nossa diversidade social brasileira nos revela que a força de disseminação dessas tecnologias esbarra em várias dificuldades trazidas inclusive pelos contextos socioeconômicos tanto em relação ao acesso quanto a qualidade do uso das TICs pelos estudantes. Nesse contexto, o professor é o meio incentivador e disseminador dessa nova tecnologia pedagógica, assim sendo, este artigo se preocupou em revelar se somente o conhecimento das TICs são suficientes para garantir uma aprendizagem qualificada. Para tal percepção foram investigadas duas escolas, municipal e estadual, do interior de São Paulo através de questionário eletrônico. Os dados analisados mostram que o conhecimento por parte dos professores acerca das TICs não garante por si a qualificação das práticas em M-learning por centrarem mais em instrumentos visuais de reprodução do que efetivamente o uso de aplicativos voltados a lógica do aprendizado. $O$ trabalho evidenciou que embora muito promissora as estratégias do M-learning ainda precisam ser melhor trabalhadas enquanto formação docente.
\end{abstract}

Palavras-chave: formação de professores; tecnologias da informação e comunicação; Mlearning. 


\begin{abstract}
M-learning or the new information and communication technologies, better known as ICTs, are present in contexts of educational discussion after 1990. However, our Brazilian social diversity reveals that the strength of dissemination of these technologies comes up against several difficulties brought about by socioeconomic contexts both in terms of access and the quality of ICTs use by students. In this context, the teacher is the stimulating and disseminating mean of this new pedagogical technology, thus this article was concerned with revealing if only the knowledge of the TICs are enough to guarantee a qualified learning. For this perception, two schools, municipal and state, from the interior of São Paulo were investigated through an electronic questionnaire. The analyzed data show that teachers' knowledge about ICTs does not guarantee the qualification of M-learning practices because it focus more on visual reproduction tools than actually on using applications focused on learning logic. This job has shown that although very promising, the M-learning strategies still need to be better worked as teacher training.
\end{abstract}

Keywords: teacher training; information and communication technologies; M-learning. 


\section{Introdução}

As Tecnologias aliadas à Educação vêm sendo discutidas desde a década de 1990, quando ocorrem grandes avanços no que diz respeito ao surgimento dessas novas Tecnologias de Informação e Comunicação. No entanto, atualmente, muito se tem discutido acerca da concepção de tecnologia, entendendo-se que ela deve ir além de somente dar condições de acesso aos sujeitos, e ser, também, uma ferramenta de interação do sujeito com o mundo, de modo crítico.

Ao mesmo tempo, o advento das novas tecnologias, em especial, as de comunicação e informação, vem disseminando conhecimento e dando alternativas para que processos educacionais ocorram.

Logicamente, não devemos esquecer que em contextos sociais mais complexos, o acesso a essas ferramentas não se dá nas mesmas condições observadas em seguimentos da sociedade mais favorecidos economicamente. Por isso é importante ressaltarmos que para a tecnologia cumprir os ensejos que dela se espera, não basta facilidade e oportunidade de acesso se não houver formas de sua consciente utilização ou, até mesmo, acesso constante à Internet, por exemplo.

No entanto, é inegável a grande contribuição dada pela tecnologia em contextos de aprendizagem, principalmente as tecnologias móveis, que permitiram maior acessibilidade e contribuem para disseminar o conhecimento e levar a possibilidade de estudo a locais não possíveis no passado recente. Cria-se um otimismo a respeito desses recursos, como se magicamente eles pudessem resolver todas as dificuldades que a educação enfrenta, incluindo o aumento da violência nos espaços escolares.

Canclini (2005) apud Barreto (2009) sinaliza que a tendência hegemônica do uso das Tecnologia da Informação e Comunicação (TIC) atende aos interesses da classe dominante, desconsiderando necessidades da maioria da população. O uso da tecnologia não se reduz a criação de pacotes tecnológicos ou a inserção de recursos limitados a materiais de ensino distanciando o processo de ensino-aprendizagem de uma possível dimensão emancipatória.

O progresso da TIC cria diferentes possibilidades de acesso e manejo da informação, criando muitas vezes um mito, da rapidez dos processos, dispensando o esforço necessário para apropriação e compreensão dos conteúdos veiculados pela escola. Consequentemente temos o sujeito apressado e sobrecarregado com tarefas que aparentemente podem ser resolvidas em um tempo curto. Na fala de alguns professores percebe-se o temor que estas ferramentas possam ocupar ainda mais o tempo do professor ampliando o trabalho realizado fora da escola e a resistência ao computador como ferramenta pedagógica, por conta dessa possibilidade de trabalho não remunerado, de modo que os tecnocratas do ensino acabem tomando as rédeas do processo educativo, com medidas de gestão burocrática Barreto (2009). Não se trata de negar a importância e o papel que estes recursos podem ter na organização de processos de ensino-aprendizagem, mas, dimensioná-los de uma forma realista considerando a complexidade do desenvolvimento humano e da escola enquanto instituição social. 
Com o desenvolvimento rápido da tecnologia, o conhecimento e a pesquisa em $\mathrm{M}$ learning tem se difundido e gerado contextos de aprendizagem diversificados. A partir do surgimento de tecnologias móveis, organiza-se uma linha de pesquisa que busca identificar, conhecer, compreender e desenvolver o uso dessa tecnologia em contextos educacionais, denominados M-learning Araújo Jr.; Silveira (2014).

Conceituar o significado do M-learning ainda é um desafio para o meio acadêmico, mas diversos autores têm se concentrado em tal tarefa, como Freysen (2004), Lehner e Nosekabel (2002), Geddes (2004) e Crompton (2013). Todos, com suas especificidades, chegam ao conceito central de que o M-learning se define pelo uso de Tecnologias de Informação e Comunicação utilizadas com objetivo educativo Araújo Jr.; Silveira (2014).

Velasco (2012) destaca que as mudanças na Tecnologia da Informação e da Comunicação não têm retrocesso, obrigando a Sociedade e os professores a aproveitar a atração que as novas tecnologias exercem nos estudantes, convertendo-as em aliadas na hora de aprender e potencializar novos valores.

Assim, a TIC (Tecnologia da Informação e da Comunicação)/TAC (Tecnologia para Aprendizagem e Conhecimento) constitui-se um novo debate e uma nova perspectiva de colaboração, que requer mais do que o domínio da própria técnica. Como afirma o autor "Las competencias digitales, relacionadas con las TIC tiene mucha tecnologia, pero em el fondo muy para metodologia" Velasco (2012).

O modelo TIC, segundo o autor, pode ser excessivamente instrumentalista, pouco motivador para as necessidades de alunos e professores do século XXI. Entretanto, a aprendizagem de enfoque M-learning é dependente direta do professor como seu interlocutor. O professor é o sujeito incentivador, motivador e propositor de espaços educativos que contemplem as possibilidades de aprendizagem despertadas pelo $\mathrm{M}$ learning.

Identificar e conhecer quais são as relações estabelecidas entre professor e tecnologia permite ampliar as discussões acerca do M-learning. Mas será que os professores inseridos nos contextos educativos atuais estão preparados para a revolução tecnológica dos novos tempos?

Sabe-se que muitos desses profissionais não possuem grande familiaridade com as novas tecnologias. Então, até que ponto esse professor é preparado para viabilizar aprendizagens com o M-learning?

As dificuldades enfrentadas devido à formação inicial dos professores são amplamente conhecidas. Em seu estudo, Gatti (2010) aborda extensamente a problemática acerca da formação de professores no Brasil. Seus resultados apontam que os licenciandos têm poucas Disciplinas que os fazem refletir sobre como construirão a metodologia de trabalho pedagógico, excessiva valorização de Disciplinas Científicas em detrimento das humanas, que caracterizam o Curso para a formação de professores, e grande parcela dos licenciandos não tem na Licenciatura a sua primeira opção de Curso, o que leva a pensar que a Licenciatura possa ser um alicerce para alcançar outras metas desses estudantes. 
Brito (2016) demonstra esses aspectos ao analisar um Curso de formação inicial de professores polivalentes, egressos de um curso de Pedagogia. Os dados demonstram a pouca familiaridade desses alunos não só com os recursos da tecnologia, mas também com o conteúdo da Matemática, tendo convergência com as pesquisas mencionadas.

Todas as questões trazidas pelo autor nos fazem refletir sobre o universo complexo da docência, que vão muito além do saber científico por si só. É necessário que o docente esteja apto a construir espaços de aprendizagem nos quais os educandos sejam capazes de verificar, analisar criticamente e contribuir com a construção de um mundo mais democrático e igualitário. Mas para o audacioso projeto, que traz suas complicações das esferas administrativas e organizacionais, o professor deve ser um entusiasta corajoso e aliar toda essa responsabilidade às constantes inovações tecnológicas; e isso não é algo simples.

O domínio dos recursos da TIC, a apropriação desses recursos como ferramentas pedagógicas, o domínio dos conteúdos a serem ensinados, assim como a concepção que o professor tem sobre o ensino, a Educação e a aprendizagem são condições importantes para o trânsito da TIC para a TAC.

Devido à estreita relação entre um dos pesquisadores e o contexto a ser investigado, é de conhecimento que a gestão incentiva os professores a utilizarem tecnologias móveis em suas aulas. No entanto, pela percepção da própria gestão, a maioria dos professores acaba utilizando as tecnologias mais como forma de facilitar seu trabalho do que como estratégia e planejamento de aprendizagem, fato apontado, principalmente, com preferência pelo recurso do Datashow.

A partir desses apontamentos, o artigo busca compreender o uso que professores fazem dos recursos da tecnologia para organizar suas aulas, em um contexto em que existe incentivo para usar essas ferramentas.

Será que o conhecimento e o acesso, por parte dos professores, de tecnologias móveis e aplicativos por si só garantem que as práticas educativas desses professores sejam qualificadas?

Para responder essa pergunta, investigaram-se duas escolas públicas de uma cidade do interior do estado de São Paulo, objetivando compreender qual era o nível de conhecimento dos docentes em relação ao uso de tecnologia, já que nesse contexto específico a gestão relata ser uma incentivadora de práticas educativas que valorizem o M-learning na escola. Descreve-se a metodologia usada na pesquisa, o instrumento de coleta de dados e analise possível a partir dos dados coletados. 


\section{Metodologia}

$\mathrm{Na}$ tentativa de entender como os professores estão se comportando em meio a essa revolução tecnológica, em que a presença das tecnologias digitais móveis tem engrenado práticas sociais que exigem uma nova postura dos educandos na Sociedade, foi realizada uma pesquisa quantitativa em duas escolas públicas, no estado de São Paulo.

Segundo Falcão e Regnier (2000), a análise de dados quantitativos constitui-se um trabalho que propicia que "a informação que não pode ser diretamente visualizada a partir de uma massa de dados poderá sê-lo se tais dados sofrem algum tipo de transformação que permita uma observação de outro ponto de vista". Completam que "a quantificação abrange um conjunto de procedimentos, técnicas e algoritmos destinados a auxiliar 0 pesquisador a extrair de seus dados subsídios para responder à(s) pergunta(s) que 0 mesmo estabeleceu como objetivo(s) de seu trabalho".

O estudo foi desenvolvido com cinquenta professores da Rede Pública Municipal e Estadual, mesclando professores do Ensino Fundamental I, II e Ensino Médio, usando o questionário como forma de coleta dos dados.

A aplicação foi realizada por meio de questionário elaborado na plataforma Google forms e se se utilizou o link <http://goo.gl/forms/VnEGj2tb2K>. Utilizar esse instrumento de coleta de dados online foi uma forma de aliar a pesquisa aos novos contextos da tecnologia, de modo a incentivar a sua utilização pelos professores, além de a plataforma do Google forms facilitar a visualização dos resultados, contribuindo para o melhor encaminhamento da pesquisa.

A aplicação do questionário deu-se durante a reunião de ATPC1, na qual foi disponibilizado acesso à Internet aos professores, que acessaram o link e responderam o questionário.

O primeiro contato do pesquisador com o campo de pesquisa deu-se por uma conversa formal entre ele e as equipes gestoras das escolas nas quais seriam realizados os trabalhos.

Na oportunidade, o pesquisador explicou que a atividade seria parte do estudo de uma das Disciplinas do Mestrado em Ensino de Ciências e Matemática e que os dados coletados serviriam de base para a confecção de um artigo na disciplina de Tendências do Uso das Tecnologias da Informação e Comunicação no Ensino, na Universidade Cruzeiro do Sul.

Depois de lerem o Projeto de Pesquisa e o questionário que seria aplicado aos professores, as diretoras de ambas as escolas sugeriram que o questionário fosse realizado durante as ATPCs, pois nessas reuniões todos os professores se encontrariam na escola, sendo possível participação total da amostra selecionada.

\footnotetext{
${ }^{1}$ Atividade de Trabalho Pedagógico Coletivo.
} 


\section{Resultados}

Os resultados coletados durante o estudo demonstram que $54 \%$ dos respondentes atuam no Ensino Fundamental I e II, enquanto $46 \%$ atuam no Ensino Fundamental II e Ensino Médio, como pode ser observado no Gráfico a seguir.

Em que nível de ensino você atua?
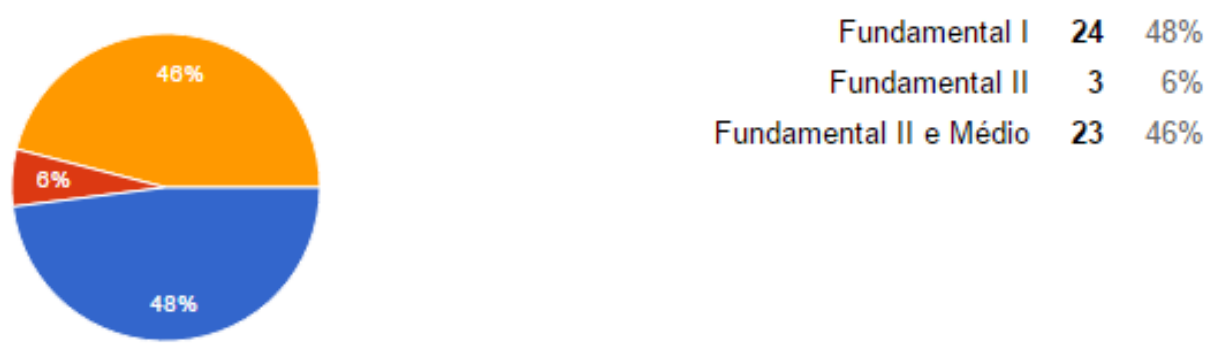

Gráfico 1 - Participantes da pesquisa e níveis de escolarização. Fonte: elaborado pelos próprios autores.

Em relação à Disciplina lecionada e à área em que ela se insere, observa-se que $48 \%$ dos participantes lecionam Disciplinas de Linguagens e Códigos; $28 \%$ Disciplinas inseridas na área das Ciências Humanas e Sociais; 14\% na área das Ciências Exatas e 10\% das Ciências Físicas e Biológicas, como se pode observar no Gráfico 2.

\section{Em qual disciplina você atua?}

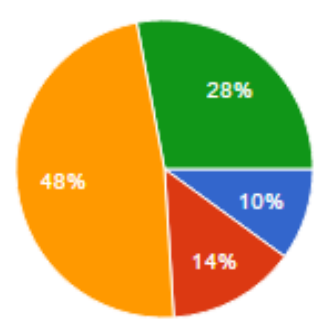

$\begin{array}{rrr}\text { Ciências físicas e biológicas } & 5 & 10 \% \\ \text { Ciências exatas } & 7 & 14 \% \\ \text { Linguagens e códigos } & 24 & 48 \% \\ \text { Ciências humanas e sociais } & 14 & 28 \%\end{array}$

Gráfico 2 - Áreas de especificidade dos professores participantes da pesquisa. Fonte: elaborado pelos próprios autores.

O tempo de experiência docente foi considerado relevante, sendo que cerca de $30 \%$ dos professores participantes têm entre 11 e 15 anos de experiência; 20\% possuem entre 16 e 20 anos; $18 \%$ até 5 anos; $16 \%$ até 10 anos; $12 \%$ até 25 anos e $4 \%$ até 30 anos de experiência, denotando ser esse um corpo docente relativamente jovem, que pode conhecer e ter acesso às tecnologias visadas nesse trabalho. 


\section{Quanto tempo de profissão docente?}

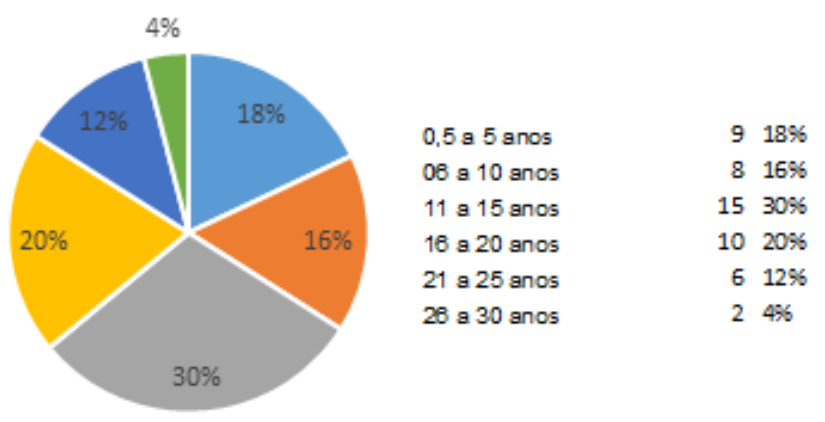

Gráfico 3 - Tempo de profissão docente do participante.

Fonte: elaborado pelos próprios autores.

Outra variável considerada relevante foi a quantidade de horas trabalhadas na semana por esses profissionais. Detectou-se que $32 \%$ trabalham até 40 horas; $26 \%$ até 50 horas; $18 \%$ até 30 horas; $16 \%$ até 55 horas; $6 \%$ até 10 horas e $2 \%$ até 20 horas de trabalho semanal.

É perceptível que a jornada de trabalho exaustiva prevalece entre os entrevistados, como podemos verificar no Gráfico 4, somando-se os percentuais relacionados às horas de trabalho superiores a 40 horas, observamos que $74 \%$ dos participantes trabalham pelo menos 40 horas semanais em mais de uma unidade escolar. Nesse contexto, encontramos o professor com pequena possibilidade de diálogo e de compartilhamento de suas experiências com seus pares.

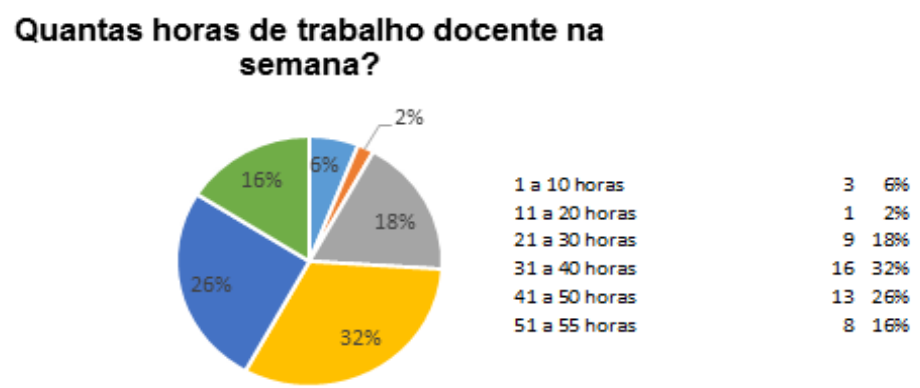

Gráfico 4 - Quantidade de horas de trabalho por semana do professor participante.

Fonte: elaborado pelos próprios autores.

Os Gráficos 5 e 6 demonstram que os professores dizem que a escola dispõe de infraestrutura tecnológica, o que confirma o relato da gestão ao pesquisador sobre 0 incentivo do uso dos mesmos recursos tecnológicos para o corpo docente.

Entretanto, a simples presença desses recursos não é suficiente para que eles se constituam recursos pedagógicos, como demonstrado no trânsito entre TIC e TAC. 
A escola em que você atua dispõe de infraestrutura para o uso de recursos tecnológicos?

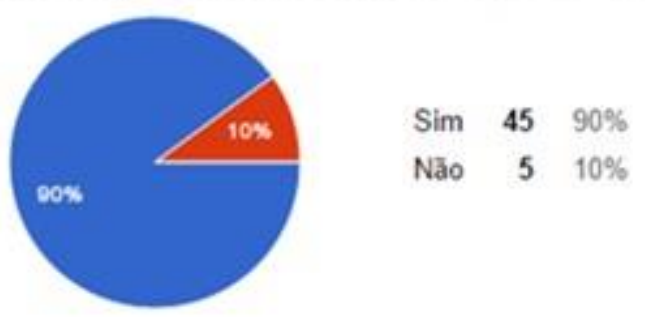

Gráfico 5 - Infraestrutura disponibilizada pela escola para os professores.

Fonte: elaborado pelos próprios autores.

\section{A escola em que você atua incentiva o uso de recursos tecnológicos?}

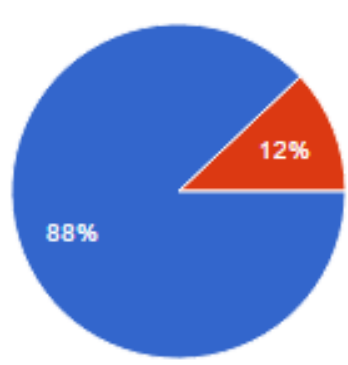

Sim $4488 \%$

Não $\quad 6 \quad 12 \%$

Gráfico 6 - Incentivo aos professores para o uso das tecnologias pela gestão.

Fonte: elaborado pelos próprios autores.

Os professores, quase na totalidade dos entrevistados, $90 \%$ a $94 \%$, possuem celular e notebook, sendo que $44 \%$ têm acesso ao tablet. Ou seja, a grande maioria dos professores tem contato com dispositivos móveis, reafirmando-se a limitação da simples presença da tecnologia

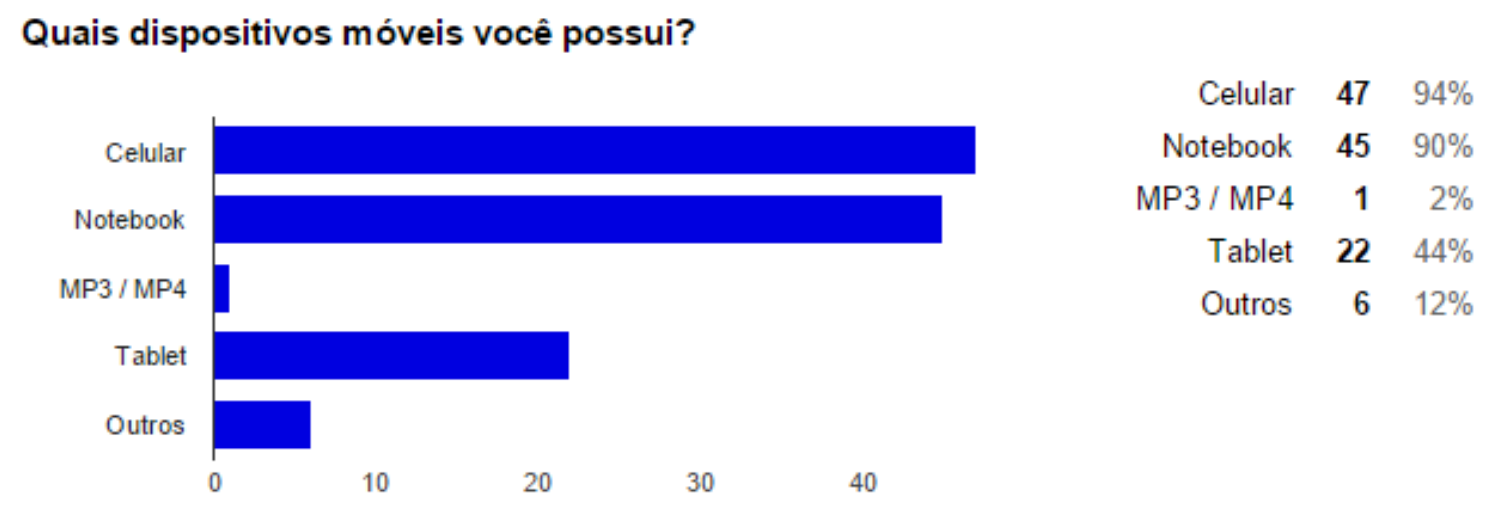

Gráfico 7 - Porcentagem de dispositivos conhecidos pelos professores participantes.

Fonte: elaborado pelos próprios autores.

Ao serem questionados sobre a capacidade do uso de dispositivos móveis contribuírem positivamente na qualidade das aulas, $46 \%$ dos professores responderam sim de maneira muito significativa; $32 \%$ sim, de maneira significativa; $20 \%$ sim, pode trazer algumas contribuições e $2 \%$ não traz contribuição. Portanto, mais de $90 \%$ dos 
entrevistados acredita que a tecnologia pode contribuir para qualificar sua prática educativa.

Você acredita que o uso de dispositivos móveis pode melhorar a qualidade de suas aulas?
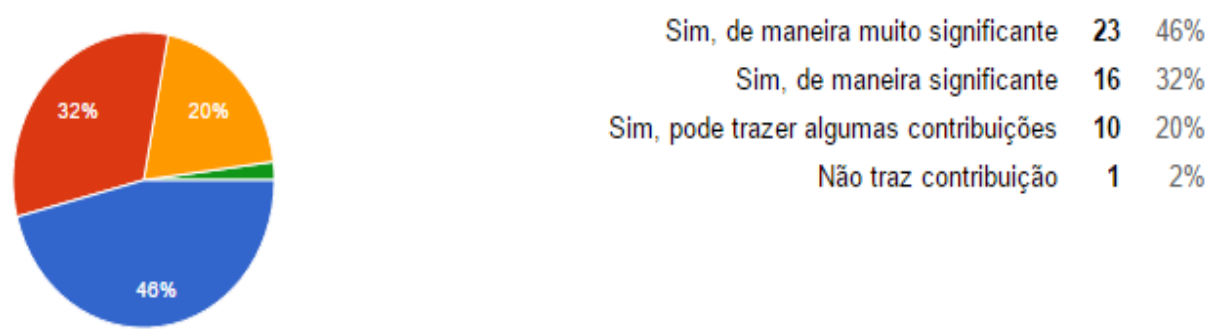

Gráfico 8 - Professores que acreditam qualificar sua prática docente com o uso de dispositivos móveis.

Fonte: elaborado pelos próprios autores.

Em relação à crença dos professores sobre o uso de dispositivos móveis e a qualidade das aulas, observamos que $92 \%$ dos respondentes dizem fazer uso de algum recurso tecnológico durante sua prática educativa, contrariando o discurso da gestão, que relata não ocorrer o uso de tecnologias durante as aulas.

No entanto, no Gráfico 10, pode-se perceber que a tecnologia mais utilizada nas práticas educativas dos entrevistados é o Datashow, seguida de notebook, lousa digital e Sala de Informática. Nota-se que outros dispositivos móveis aparecem muito dispersos nos resultados, pois um ou outro professor utiliza celular ou tablet nas aulas, ou recursos como vídeo.

Você faz uso de algum recurso tecnológico durante suas aulas?

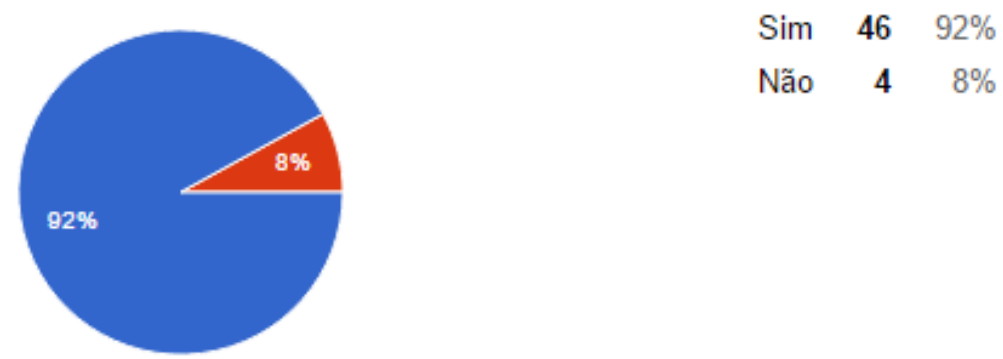

Gráfico 9 - Utilização de recursos móveis nas aulas pelos professores.

Fonte: elaborado pelos próprios autores. 


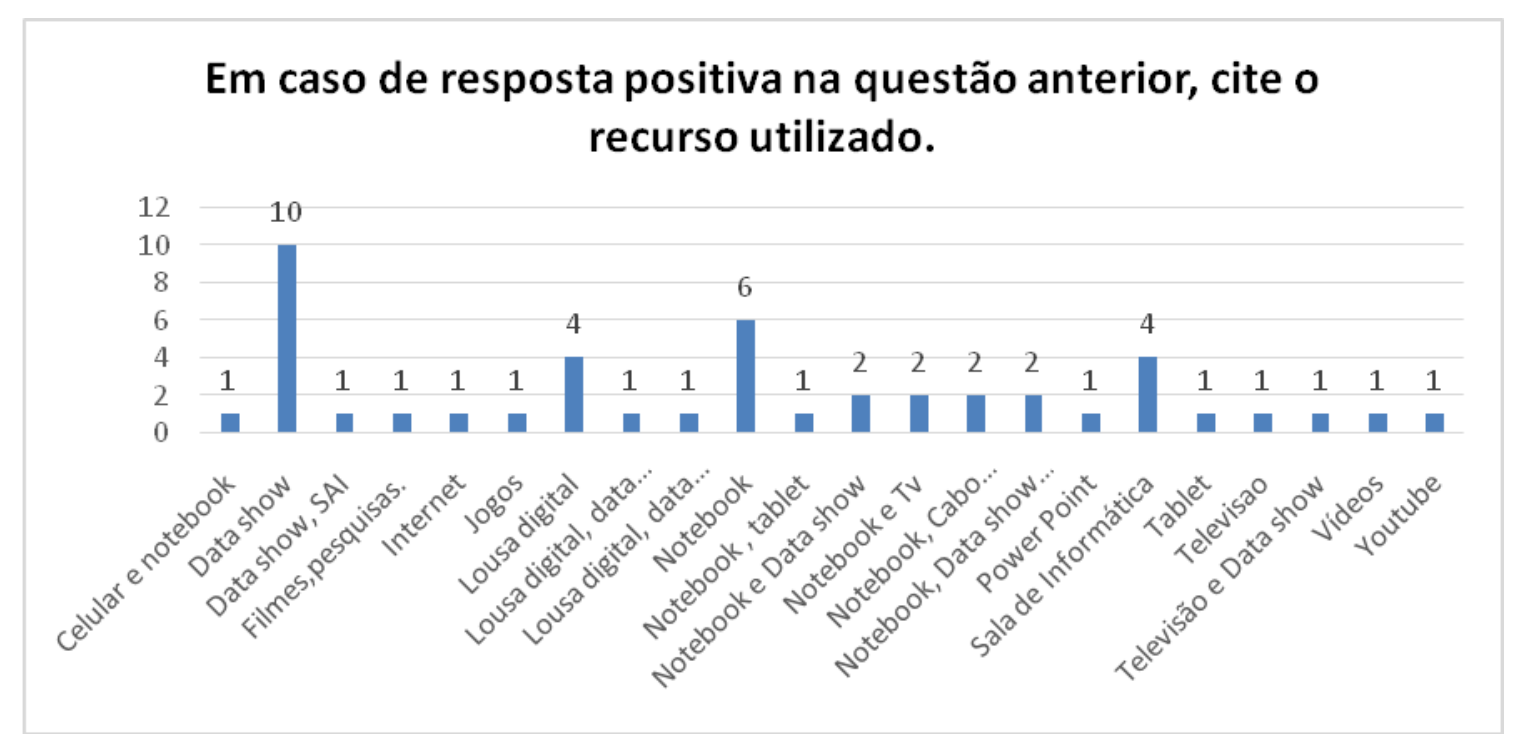

Gráfico 10 - Tipos de dispositivos móveis utilizados pelos entrevistados.

Fonte: elaborado pelos próprios autores.

Considerando que $42 \%$ dos professores afirmam que recebem capacitação e $58 \%$ negam que a recebam, como demonstrado no Gráfico 11, optou-se por uma nova reunião com a diretoria, de modo a obter outros dados sobre essa percepção.

A diretora da escola de Ensino Fundamental I relatou, como se observa em seu discurso, que seus professores realmente nunca receberam capacitação específica sobre o assunto e que utilizam a Sala de Informática com conhecimentos que trazem de casa:

\begin{abstract}
Eu, a vice e a coordenadora incentivamos os professores a usarem a Sala de Informática, inclusive, sempre deixamos um tempo no ATPC para que pesquisem e preparem suas aulas de forma mais dinâmica, mas o problema é que também não somos boas com tecnologia. Quando os docentes precisam usar algum recurso de informática sugerido na apostila e que não sabem, chamamos o secretário da escola, pois ele tem um conhecimento maior.
\end{abstract}

Diretora, vice-diretora e coordenadora não dominam a tecnologia de modo suficiente para ajudar os docentes em suas dúvidas. Ainda que reconheçam o valor desses recursos, liberando o tempo da ATPC, fica a cargo do domínio de cada professor o uso dos recursos.

Já a diretora da escola de Ensino Fundamental II e Médio relatou que, embora em tempo reduzido, seus professores são capacitados por um professor do PCNP (Professor Coordenador do Núcleo Pedagógico) da Diretoria de Ensino da qual fazem parte. Sua fala também merece destaque.

Diz a entrevistada:

Toda vez que os professores recebem uma capacitação, começam a usar os recursos tecnológicos oferecidos pela escola, mas o problema é que depois de um tempo isso cai no esquecimento. Talvez se fossem capacitados mais vezes... Neste ano mesmo, receberam apenas uma capacitação.

O que a entrevistada destaca é o estímulo inicial que a capacitação e os recursos produzem nos professores e a descontinuidade no uso desses recursos, que acabam não sendo incorporados como recursos pedagógicos. 


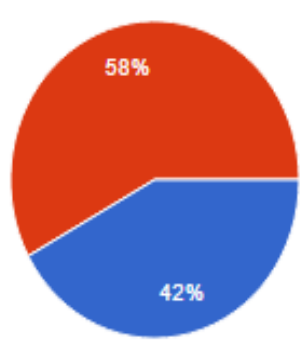

Sim $21 \quad 42 \%$

Não $\quad 2958 \%$

Gráfico 11 - Capacitações referentes ao uso de Tecnologias na Educação.

Fonte: elaborado pelos próprios autores.

Em caso de resposta positiva na questão anterior. Há quanto tempo foi a sua última capacitação?
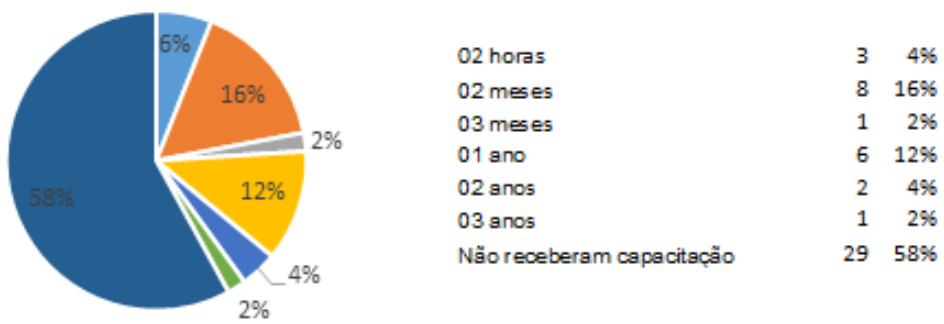

Gráfico 12 - Frequência de capacitações recebidas pelos professores.

Fonte: elaborado pelos próprios autores.

O Gráfico 13 demonstra que $42 \%$ dos respondentes declaram não ter conhecimento sobre aplicativos educacionais, em oposição a 58\%, que declara conhecêlos, ainda que não explicitem quais conhecem. Esses dados reafirmam a pequena contribuição que a TIC oferece a esses professores na organização de contextos de ensino.

Você conhece alguma aplicativo educacional?

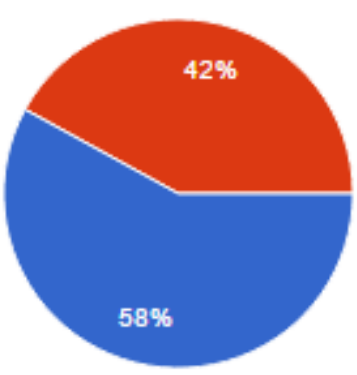

$\begin{array}{lll}\text { Sim } & 29 & 58 \% \\ \text { Não } & 21 & 42 \%\end{array}$

Gráfico 13 - Conhecimento dos professores em relação a aplicativos educativos.

Fonte: elaborado pelos próprios autores.

Quando questionados sobre o porquê de não utilizarem aplicativos educativos durante sua prática pedagógica, a resposta com maior percentual (48\%) é: "Não tenho familiaridade com os aplicativos". Esse dado é extremamente relevante, porque demostra que conhecer é diferente de estar apto a utilizar um recurso como esse. 
Comparando o Gráfico 13 ao Gráfico 14, observa-se que 10\% dos que declaram conhecer algum aplicativo educacional também declaram não ter feito uso dele. Somados aos $52 \%$ que declaram não ter feito uso desses recursos, temos $62 \%$ dos respondentes que não incluem a TIC na organização da sua prática docente, reafirmando dados das questões anteriores.

Já fez uso de algum aplicativo durante as aulas?

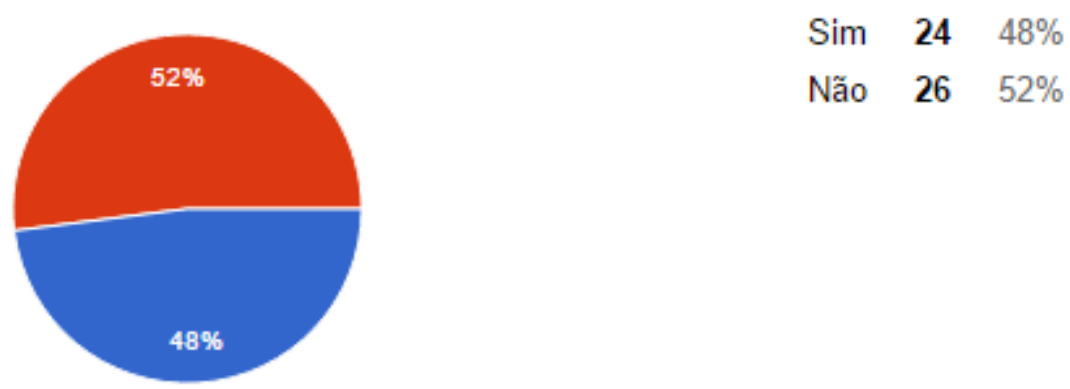

Gráfico 14 - Professores que já fizeram uso de aplicativos nas aulas. Fonte: elaborado pelos próprios autores.

Por que você não utiliza os aplicativos educacionais com mais frequência?

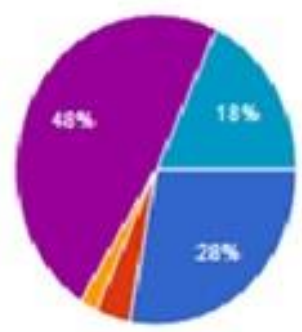

Esta pergunta não me cabe, pois faço uso com frequência Não há recursos Perco muito tempo para atualizá-los Os alunos ficam muito agitados com novos recursos Não tenho tanta familiaridade, por isso tenho receio de utilizá-los

Outros

Gráfico 15 - Motivos da não utilização dos aplicativos educacionais em suas aulas pelos professores.

Fonte: elaborado pelos próprios autores.

Por fim, mostra-se relevante o anseio dos professores por maior capacitação para possibilitar o uso qualificado de recursos tecnológicos na Educação, como demonstra o Gráfico 16, pois $94 \%$ dos entrevistados gostariam de receber tais capacitações.

Você gostaria de receber mais capacitações para utilização de novos recursos tecnológicos?

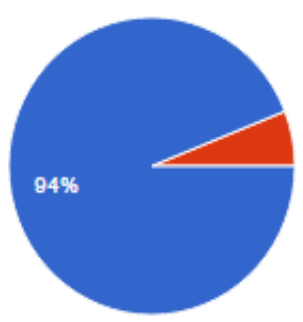

Sim $47 \quad 94 \%$

Não $36 \%$

16 - Entrevistados que gostariam de maior número de capacitações na área.

Fonte: elaborado pelos próprios autores.

Gráfico 
A gama de resultados coletados neste trabalho nos traz algumas questões relevantes para a aprendizagem por meio dos recursos M-learning. O relato da gestão que desencadeou tal trabalho dizia que nas escolas havia incentivo para 0 uso de recursos tecnológicos, mas que os professores não o faziam ou os utilizavam mais como instrumento facilitador do trabalho pedagógico do professor do que como estratégia planejada de aprendizagem.

Os dados nos mostram que o professor tem informação dos dispositivos móveis com potencial para uso em práticas educativas, mas seu uso foi relatado por uma parcela pequena dos docentes.

Os recursos mais usados são o Datashow, o notebook, a Sala de Informática e a lousa digital. Esses recursos estão muito próximos daqueles usados em contextos de ensino considerados tradicionais, marcados pela passividade dos alunos, ainda que sejam mais sofisticados.

Os entrevistados afirmaram, também, que o não uso se relaciona à falta de familiaridade com os aplicativos educacionais. Tal dado revela que o simples conhecimento e a utilização pessoal de dispositivos móveis não são suficientes para oferecer segurança ao professor para construir práticas de aprendizagem que envolvam as tecnologias móveis. Ou seja, como demonstra Gatti (2010), o uso da TIC como recurso pedagógico não depende apenas do domínio que o professor tenha desse recurso, mas também de outras circunstâncias relacionadas à sua formação, que variam desde a ênfase nos conteúdos das Disciplinas até as questões metodológicas. O trânsito da TIC para a TAC exige a superação da dimensão instrumental da primeira.

Tal análise merece preocupação, pois ao mesmo tempo em que o M-learning tem aumentado significativamente as possibilidades e o conhecimento de alternativas de aprendizagem, como podemos verificar no artigo escrito por Wu e Kao (2012), o aumento considerável de conhecimento acerca do M-learning parece não chegar aos difusores de conhecimento, os professores, na mesma velocidade com a qual é produzido.

Uma vez que o professor os desconhece ou pouco os conhece, esse conhecimento fica centrado nas discussões acadêmicas, inviabilizando seu potencial educativo. Essa evidência leva a pensar que seria necessário criar modos de difundir os conhecimentos M-learning nas instituições escolares, em um esforço capaz de difundir e contribuir enormemente para essa área de conhecimento. 


\section{Considerações finais}

As informações produzidas e analisadas neste estudo foram expressivas, o que colaborou para admitir, por meio de um processo científico, o que muitas pessoas já manifestavam a respeito do uso das tecnologias pelos professores, nas escolas analisadas.

A formação de professores para o uso de novas tecnologias é de grande importância para o desenvolvimento do processo de ensino e aprendizagem, pois auxilia o professor pedagogicamente. Aponta-se, ainda, que a maioria dos professores desconhece alguns recursos tecnológicos.

Esses dados apontam para a necessidade da oferta de Cursos de atualização dos professores na modalidade de formação continuada. Os dados deste estudo demonstram, também, a necessidade de ampliar a compreensão da relação dos professores com os recursos da tecnologia, trazendo inúmeras questões que sugerem novos estudos para compreender a complexidade da potencialidade do M-learning nos contextos educativos, pois os professores dizem trabalhar com os dispositivos de tecnologia, mas não demonstram claramente como o fazem.

Os dados revelam que o dispositivo mais utilizado pelos professores é o Datashow que, por sua vez e por sua especificidade tecnológica, permite tanto a reprodução de conteúdo, quanto a qualificação das aulas, dependendo de como o professor maneja essa ferramenta.

Essas questões estão ligadas diretamente à concepção que o professor tem de tecnologia aplicada à Educação e essa variável não foi considerada neste estudo.

No M-learning, a cada dia, desenvolvem-se mais aplicativos educacionais para suprir as necessidades de aprendizagem a fim de potencializar as tecnologias; no entanto, os aplicativos são pouco conhecidos pelos professores.

Por fim, é necessário explicitar que incentivar os professores não significa ser capaz de desenvolver estratégias M-learning em contextos educativos, pois os dados mostram que, embora os professores tenham conhecimentos acerca das tecnologias, eles também relatam não ter capacitação suficiente para preparar estratégias de aprendizagem M-learning.

Como mencionado anteriormente, os dados coletados neste trabalho levam-nos a refletir sobre outras questões que envolvem o M-learning, o professor e a aprendizagem. 


\section{Referências}

ARAUJO JUNIOR, C. F.; SILVEIRA, I. F. Tablets no Ensino Fundamental e Médio: princípios e aplicações. São Paulo: Terracota, 2014.

BARRETO, R. G. Discursos, tecnologias, educação. Rio de Janeiro: EdUERJ, 2009.

BRITO, A. S. Jogos pedagógicos digitais na formação inicial de professores que ensinam matemática nas séries iniciais do ensino fundamental. 2016. $113 f$. Dissertação (Mestrado em Ensino de Ciências e Matemática) - Universidade Cruzeiro do Sul, São Paulo, 2016.

CROMPTON, H. Mobile learning: new approach, new theory. In: BERGE, Z. L.; MUILENBURG, L. Y. (Ed.). Handbook of mobile learning. New York: Taylor \& Francis, 2013.

FALCÃO, J. T. R.; REGNIER, J. Sobre os métodos quantitativos na pesquisa em ciências humanas: riscos e benefícios para o pesquisador. Revista Brasileira de Estudos Pedagógicos, Brasília, v. 81, n. 198, p. 229-243, maio/2000.

FREYSEN, J. M-Learning: an educational perspective. In: ATWELL, J. E.; SAVILLSMITH, C. (Org.). M-Learn: mobile learning anytime everywhere. London, UK: [S.n.], 2004.

GATTI, B. A. Formação de Professores no Brasil: Características e Problemas. Educ. Soc., Campinas, v. 31, n. 113, p. 1355-1379, out.-dez., 2010.

GEDDES, S. Mobile learning in the 21st century: venefit for learners. Knowledge Tree e-journal, 2004. Disponível em: <https://olt.qut.edu.au/udf/OLTCONFERENCEPAPERS/gen/static/papers/Cobcroft_ OLT2006_paper.pdf>. Acesso em: 1 jul. 2014.

LEHNER, F.; NOSEKABEL, $H$. The role of mobile devices in e-learning: first experiences with a wireless-learning environment. In: INTERNATIONAL WORKSHOP ON WIRELESS AND MOBILE TECHNOLOGIES IN EDUCATION (IEEE), 2002, Vaxjo, Sweden.

VELASCO, R. A. Tecnologías para el aprendizaje y el conocimiento. Disponível em: <http://www.slideshare.net/ravsirius/tecnologas-para-el-aprendizaje-y-elconocimiento>. Acesso em: 9 out. 2016. WU, Y. J.; KAO, H. Y. Review of trends from mobile learning studies: a meta-analysis. Computers\&Education, Taiwan, 59, p.817-827, 2012. 